\title{
Tech-Levee-Watch: experimenting an integrated geophysical system for stability assessment of levees
}

\author{
Greta Tresoldi (1), Diego Arosio (2), Azadeh Hojat (1,3), Laura Longoni (1), \\ Monica Papini (1) \& Luigi Zanzi (1)
}

(1) Dipartimento di Ingegneria Civile e Ambientale, Politecnico di Milano, Piazza Leonardo Da Vinci 32, 20133 Milano, Italy
(2) Dipartimento di Scienze Chimiche e Geologiche, Università di Modena e Reggio Emilia, via Giuseppe Campi 103, 41125 Modena, Italy
(3) Department of Mining Engineering, Shahid Bahonar University of Kerman, Jomhouri boulevard, Kerman, Iran

Corresponding author e-mail: greta.tresoldi@polimi.it.

Document type: Short note.

Manuscript submitted 16 October 2017; accepted 11 December 2017; editorial responsibility and handling by S. Crema.

\section{ABSTRACT}

The aim of the Tech-Levee-Watch project is to combine geophysical technologies into an integrated system of diagnosismonitoring-alert related to the vulnerability of earthen levees.

A first milestone of the project consists in validating a fast scanning methodology based on a proper combination of portable geophysical instruments tailored to detect possible unstable areas of the levee structures. A second milestone consists in monitoring the most critical sites by installing a low-power fully-automatic geo-resistivity meter prototype programmed for wireless daily transmission of resistivity maps. The third milestone is the calibration of a relation between resistivity values and water content values so that resistivity maps will be transformed into water content maps used to feed a simulator of the levee stability. The final milestone consists of calibrating a set of thresholds in order to define an earlywarning procedure to be delivered to administrations and citizens.

This procedure can help authorities to organize maintenance of the embankments and to face critical situations that can lead to economic damages and loss of human lives.

KEY WORDS: geophysical monitoring, permanent geo-electrical monitoring, time lapse DC-resistivity, levee seepage, levee monitoring.

\section{INTRODUCTION}

Embankments are considered as the last defensive barrier to protect surrounding areas from the destructive power of water. Therefore, stability assessment of levees plays a very important role in flood prevention.

Consorzi di Bonifica are the public authorities in charge of managing rivers and irrigation canals in Italy, being responsible for controlling and maintaining the integrity of embankments. Unfortunately, an objective and validated strategy to assess the stability of levees is missing and the current monitoring procedure is mainly based on visual inspections. As a result, the assessment is highly operatordependent and takes into account only the external signs of levee deterioration which might be missing for some types of instability problems. Piping is one of the most critical phenomena which can lead to instability of earthen levees. It is defined as localized seepage that removes fine soil particles and, in the worst conditions, results in levee breaches. This problem is difficult to be detected during its early stage and can be observed only when the instability process is at an advanced level. Moreover, this effect can be triggered or worsened by excavation of rodents' burrows that are often hidden within inaccessible places and cannot be detected in advance.

Recently, several authors tested the capability of remote sensing techniques, such as laser scanning and photogrammetry, to monitor levees and riverbanks (Tournadre et al., 2014; Longoni et al., 2016; Bakula et al., 2017). Although these devices can provide very highresolution measurements, they only allow displacements to be detected at the surface, while the inner situation of the levee body remains unknown.

In the last decades, geophysical methods have been largely used to evaluate the conditions within the levee body, because they are non-invasive and cost-effective methodologies that can be used to assess the properties of embankments in terms of soil characteristics and water saturation.

Many studies are reported that include measurement sessions carried out to understand the origin of instability problems in earthen levees (e.g., Fauchard \& Mériaux, 2007; Asch et al., 2008; Chambers et al., 2008; Cardarelli et al., 2010; Gillip \& Payne, 2011; Hayashi \& Inazaki, 2013; Perri et al., 2014; Busato et al., 2016) or instability phenomena in general (Lapenna et al., 2005; Cho \& Yeom 2007; Piegari et al., 2008; Al-Fares, 2014; Malehmir et al., 2016; Wodajo \& Hickey, 2017). However, only in few studies a permanent monitoring system is implemented (Kuras et al., 2009; Hilbich et al., 2011; Supper et al., 2012; Supper et al., 2014; Weller et al., 2014) and it is often dedicated to landslide prediction or dam monitoring projects. Moreover, no established strategy has been developed so far to define a comprehensive diagnosis-monitoring-alert procedure using diverse geophysical methodologies (Fig. 1).

The first objective of the Tech-Levee-Watch (TLW) project is addressed by testing vehicle-mounted systems (Electromagnetic devices and Ground Penetrating Radar (GPR) arrays) to scan several tens of kilometers per day in order to detect potentially unstable zones of the embankments. GPR is a popular geophysical method 
1.1 Radar and Electromagnetic portable devices
3.1 Calibration of resistivity/water content function

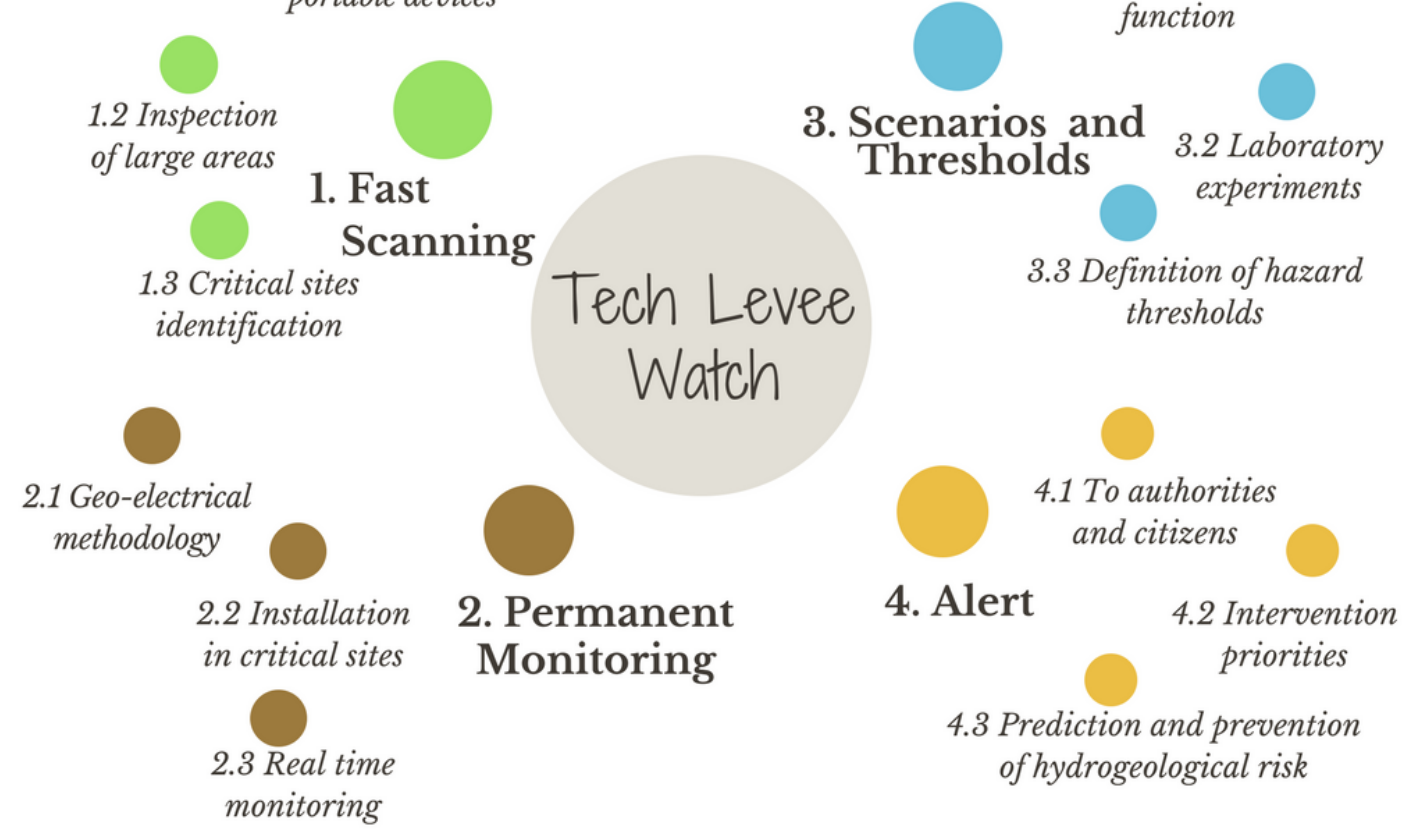

Fig. 1 - Different phases of the Tech-Levee-Watch project.

that has already gained some credibility as an effective method for the assessment of levee conditions (Di Prinzio et al., 2010; Chlaib et al., 2014; Inazaki et al., 2016). More specifically, it is especially used to detect holes in the levee body, which in most cases are rodents' burrows. Unfortunately, its penetration is severely limited in earth structures that often consist of lime or clay and that might reach high levels of water content. Therefore, the method can be successfully used to assess only the upper section of the levee and care must be taken to plan the measurements in the driest season and/or after long periods of water shortage in the channel. Electromagnetic measurements can extend the assessment to the lower levels of the levee structure, although with lower resolution compared to GPR. More specifically, they can underline layers with different characteristics and permeability such as sand lenses where seepage and erosion phenomena can easily occur. This combination of high and medium resolution scanning methods has been already tested and the results are promising (Morelli \& Francese, 2013; Francese \& Monteiro Santos, 2014; Wermette et al., 2015). Thus, one of the objectives of the TLW project will be to validate this integration of techniques as a rapid, low cost and nondestructive solution that should be regularly applied to produce an overview of the inner situation of channel or river embankments and to detect critical situations or first symptoms of new seepage phenomena.

When the most critical sites are detected, the managing authority can decide either to perform immediate maintenance works or to install a monitoring system for any of the critical sites. Installation of a long-term monitoring system dedicated to levee stability is important where critical sites are present but also where exposure of the surrounding land is high, for example, where rivers and canals cross villages and cities. The monitoring system developed in this project is based on geo-electrical measurements performed by an array of buried electrodes. To demonstrate the feasibility and cost-effectiveness of this method, the project tests and validates a custom prototype which is specifically developed to reduce the costs compared to the commercial general-purpose equipment, to reduce power consumptions through adapting the technology to a permanent installation powered by solar panels, and to make the system fully automatic and wireless connected for daily data transmission and remote control. The next step of the project is to define quantitative thresholds for the occurrence of the levee breach based on water content values derived from resistivity measurements. This objective can be accomplished by calibrating a relationship between resistivity and water content values as well as by performing laboratory experiments and numerical simulations of seepage and levee instability. The final step, which is the most important for the safety of the people living close to levee areas, is dedicated to designing an alert procedure to warn authorities and citizens about dangerous situations and possible extreme events.

The abovementioned steps would provide the managing authorities with a useful tool for both maintenance and extraordinary works, with the final aim of mitigating and preventing hydrogeological risks. In the following, we describe in more details the most innovative part of the project consisting in the development and calibration of the monitoring system.

\section{MATERIALS AND METHODS}

A preliminary prototype of the permanent geoelectrical monitoring system (Arosio et al., 2017) was installed on an earthen levee of an irrigation canal near 
Mantova (Northern Italy). The bed of the canal is covered by a partially deteriorated concrete liner and a lateral moat collects seepage water. The channel is very close to nearby houses in this area, thus necessitating an increased attention to the hydrogeological risk assessment. The concrete liner is supposed to protect the base and the internal sides of the levees from water erosion and from rodent attacks. Unfortunately, these protection structures are sometimes hiding erosion phenomena occurring behind deteriorated segments of the liner, in a space between the liner and the earth structure that progressively increases reducing the stability of the structure. Thus, the liner increases the resistance of the structure to water erosion but can also delay the detection of hidden seepage and erosion phenomena, which cannot be observed with the visual inspection protocol. The presence of the liner and the high exposure of the site are the main motivations that lead to the selection of this site for the installation of a permanent monitoring system.

The system is still operating and daily data have been collected since September 2015 with a few short disruptions due to minor system failures. Since inhomogeneous filtration is one of the most common causes that can produce stability problems and result in levee breach, the aim of the monitoring system is to control the inner conditions of the embankment in terms of saturation and seepage.
Resistivity is a physical quantity that is changed according to different parameters: soil grain size, porosity, salinity, temperature and water content (Archie, 1942). The dependence of resistivity on water content makes it possible to detect highly saturated zones resulting from intense seepage phenomena.

The prototype of resistivity-meter was designed in order to meet the following requirements. First, unlike portable commercial devices, the system had to be installed permanently, thus facing possible attacks of rodents to the buried parts. According to this, mechanically resistant components were selected to protect the cables and the electrodes were designed to ensure long-term ground coupling. Another important requirement was that the system could work autonomously and the acquisition parameters could be remotely updated. Thus, the system is powered by a battery recharged by a solar panel, the electronics of the control unit have been designed to minimize power consumption and a mobile phone modem is used to ensure a two-way communication for remote control and data transmission.

The resistivity meter was installed on the top of the levee (Fig. 2.b), with two $23 \mathrm{~m}$ cables deployed in a $0.5 \mathrm{~m}$-deep trench (Fig. 2.a) equipped with 48 stainless steel plate electrodes and protected with an anti-rodent plastic case (Fig. 2.c). The device measures resistivity values

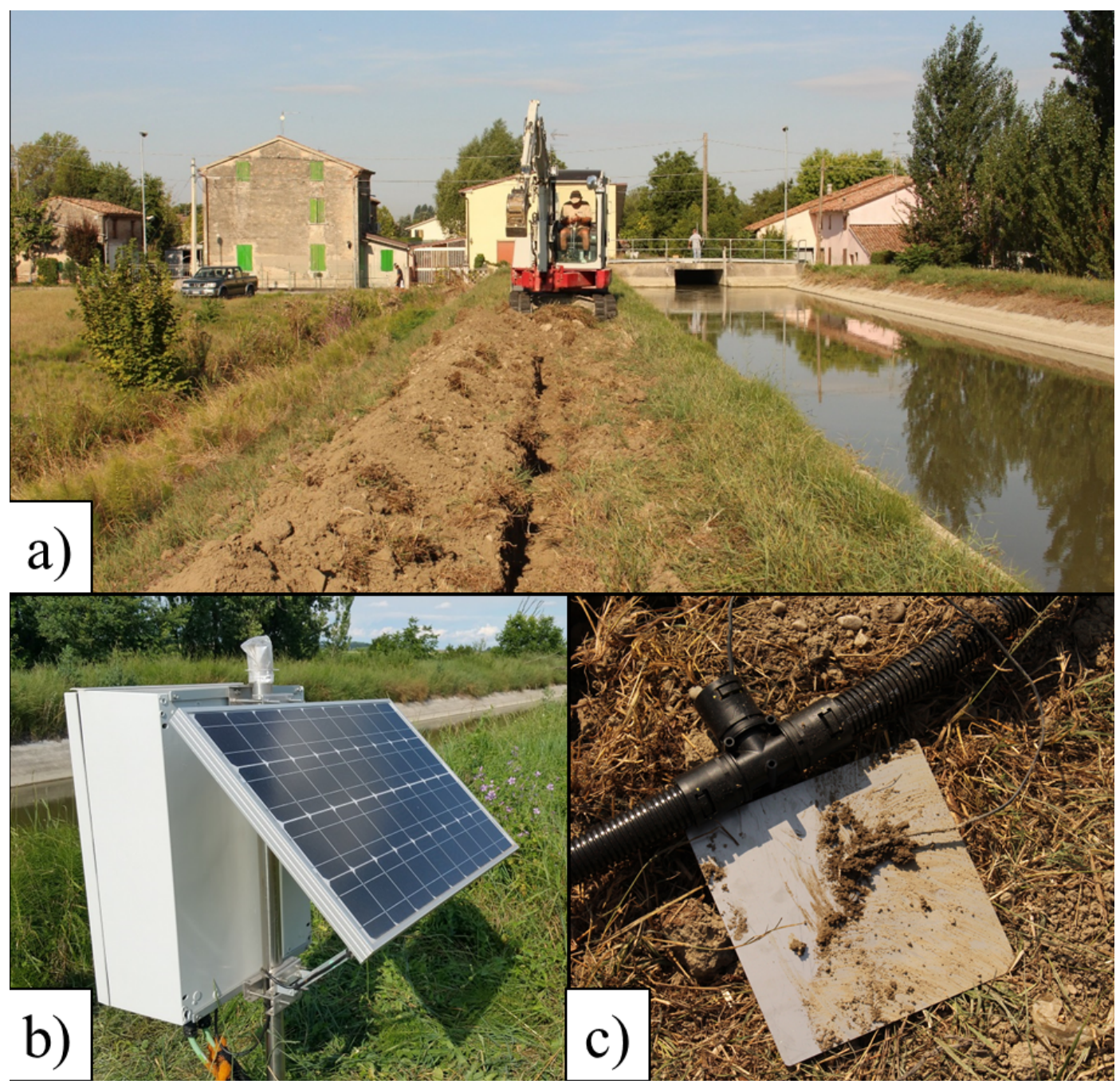

Fig. 2 - a) Trench excavation; b) The solar panel and the box containing the resistivitymeter; c) Stainless-steel plate electrode and antirodent plastic case for cable protection. 
with the Wenner configuration with $1 \mathrm{~m}$ spacing, so that the expected penetration depth is about 8 meters, with a horizontal resolution of $1 \mathrm{~m}$ and a vertical resolution of $0.5 \mathrm{~m}$. A meteorological station and an ultrasonic water level meter were also installed to correlate resistivity variations with external variables, such as rainfalls, water level, air and soil temperature.

The apparent resistivity values measured by the prototype were periodically compared with the values measured by a commercial resistivity-meter (IRIS SyscalPro) using standard rod electrodes planted on the surface of the levee. These comparisons provided consistent results with differences of only $2-3 \Omega \mathrm{m}$, corresponding to a misfit of about $10 \%$, which were mainly due to the difference in the depth of the electrodes. The commercial device, working with rod electrodes planted on the surface of the structure, measures resistivity values of the top surface of the levee that are higher in summer due to the dry soil and are lower in winter due to more frequent rainfalls. As a result, the comparison of prototype and commercial systems is affected by a small bias of a few $\Omega \mathrm{m}$ with a sign that depends on the surface situation.

\section{RESULTS AND DISCUSSION}

The monitoring system measures apparent resistivity values at the study site with a constant time interval, which is currently set at $24 \mathrm{~h}$, although the frequency of measurements can be modified according to the alert status. Since the resistivity of soil structures is strongly influenced by the water content, resistivity maps can be interpreted as qualitative maps of the distribution of water in the levee. By comparing the pseudo-sections of measured resistivity values in different times, we observe seasonal trends of electrical properties of the soil: the conductivity of the levee body slowly increases during the irrigation period, while resistivity maps move towards higher values during winter. The monitoring procedure includes inversion of apparent resistivity maps in order to study the real position and entity of the conductive zones.

Since the monitoring system is thought to be controlled by local authorities with the aim of protecting people from floods, an alert procedure based on soil water content thresholds is being implemented. To obtain quantitative maps of the soil water content from resistivity maps, a calibration of the resistivity relationship with the water content is needed. To accomplish this task, the levee body was manually drilled to extract ten samples down to a depth of three meters, corresponding almost to the basement of the embankment. The samples were analyzed in the laboratory to measure their water content. The apparent resistivity data measured by the monitoring system were inverted using Res2dInv software, and the resistivity values at the drilling point were compared with the water content values obtained in the laboratory. Experimental data were fitted with a power function that was properly calibrated to minimize the misfit. As shown in Fig. 3, resistivity and water content are inversely proportional: higher levels of water content correspond to lower resistivity values. The obtained equation is empirical and depends on the site characteristics. A new installation on a different site could make use of the same relation only if there is strong

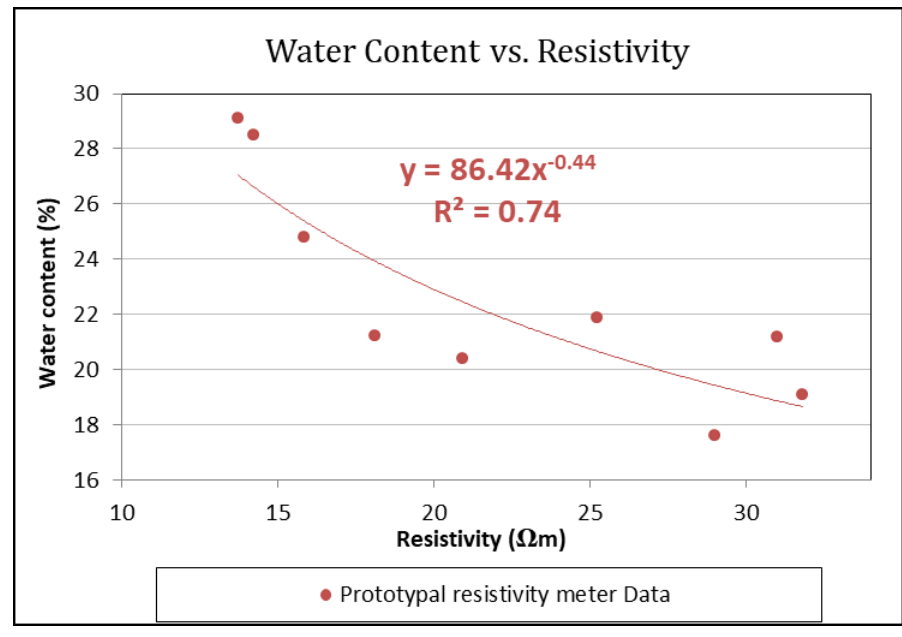

Fig. 3 - Water content relationship with resistivity.

evidence that the earth structure was built in the same way and with the same material. Thanks to this relationship, resistivity maps can be transformed into water content maps. Two examples of such translations are shown in Fig. 4, where winter and summer situations are compared: the irrigation canal is empty during winter (Fig. 4.b) and the levee soil (down to the depth of $3.80 \mathrm{~m}$ ) is characterised by a quite homogenous water content (20\%), except for the shallow part that, due to the rainy period, shows a higher percentage (30\%); when the water level in the canal reaches the maximum height in summer (Fig. 4.d), water content distribution becomes non homogenous, with some parts of the levee body experiencing a more intense seepage while the shallower part becomes drier due to the lack of rainfalls. In both cases, the deeper part of the tomographic maps (below $3.80 \mathrm{~m}$ ) is not particularly interesting for this study because it is representative of the clay soil of the site under the levee body.

Water content maps can be used to detect zones characterised by intense seepage or to analyse time variations of saturation that can lead to instability, but can be also used as an input for seepage and stability analysis in order to quantitatively understand the response of the structure to different situations of saturation, as planned in the third phase of the project. Finally, to correlate water content values derived from the monitoring procedure to breach scenarios, laboratory experiments with an embankment model and miniature resistivity arrays will be carried out to define water content thresholds that can lead to failure. In this way, permanent monitoring becomes the starting point of a more effective strategy for mitigation and prevention of hydrogeological risks, providing a means to understand the inner situation of the levee in an objective way and to relate the situation to a risk level.

\section{CONCLUSIONS}

A comprehensive procedure of diagnosis-monitoringalert is designed to deal with hydrogeological risk related to the levee instability by integrating diverse geophysical techniques. The modus operandi combines a fast scanning 


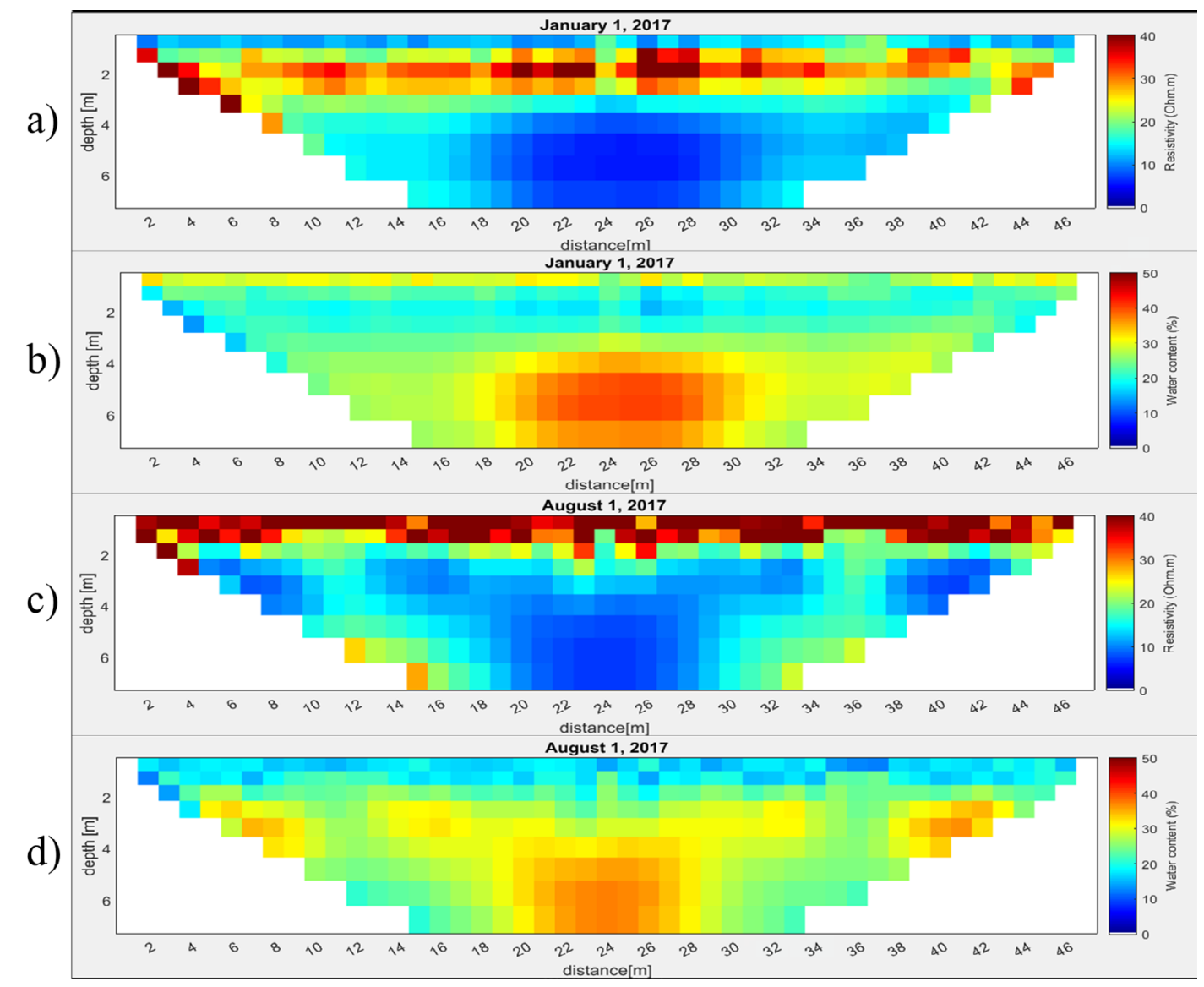

Fig. 4 - Examples of resistivity and water content maps: a) inverted resistivity and b) water content maps on a winter day; c) inverted resistivity and d) water content maps on a summer day. The surface of the soil is much drier during the summer thus showing higher resistivity and lower water content. The levee body from about $1 \mathrm{~m}$ to $3.5 \mathrm{~m}$ depth is drier during the winter when the channel is empty and saturates during the summer when the channel is used for irrigation; thus, this depth range shows lower resistivity and higher water content values during the summer. The very low resistivity values observed at a greater depth below the base of the levee structure are due to a clay layer. procedure performed with vehicle-mounted GPR and EM devices, aimed at detecting areas of potential instabilities, with a new generation of geo-electrical monitoring system for long-term control of the most critical sites. The development of the geo-electrical monitoring system is at an advanced stage. A prototype has been operating for two years and a new prototype will be installed in near future. The prototypal resistivity meter is not demanding in energy and it is much cheaper than the available commercial devices. Another advantage of the system is that it works and can be programmed remotely. The device is currently programmed to measure the resistivity values of the levee body every 24 hours and to send the data through an internet connection. Thus, the inner situation of the embankment is monitored every day. Using resistivity data, a relationship between resistivity and water content has been calibrated to transform resistivity maps into water content maps in order to underline saturation of the structure and monitor its spatial and temporal changes. Moreover, water content maps can be used as an input data for numerical seepage and stability analysis to define the behavior of the structure with changing external conditions. Ongoing laboratory experiments on a scaled model of levee using miniature cables and electrodes will help to correlate water content values to instability scenarios obtained from seepage and stability analysis and to define proper thresholds for early warning. As planned in the fourth phase of the project, an alert procedure will be defined to warn authorities and citizens in case of any possible levee breach, giving the possibility of avoiding a natural disaster.

\section{ACKNOWLEDGMENTS}

The prototype of resistivity-meter has been developed in collaboration with LSI-Lastem. This research was partially funded by Fondazione Cariplo, grant $n^{\circ}$ 2016-0785. The authors would like to thank Consorzio di Bonifica Terre dei Gonzaga in Destra Po for collaboration and assistance.

\section{REFERENCES}

Al-Fares W. (2014) - Application of electrical resistivity tomography technique for characterizing leakage problem in Abu Baara Earth Dam, Syria. Int. J. of Geophys., Volume 2014.

Archie G. E. (1942) - The electrical resistivity log as an aid in determining some reservoir characteristics. Pet. Transactions of AIME, 146, 54-62.

Arosio D., Munda S., Tresoldi G., Papini M., Longoni L. \& Zanzi L. (2017) - A customized resistivity system for monitoring saturation and seepage in earthen levees: installation and validation. Open Geosciences, 9, 457-467.

Asch T.H., Deszcz-Pan M., Burton B.L. \& Ball L.B. (2008) - Geophysical characterization of American River levees, Sacramento, California, using electromagnetics, capacitively coupled resistivity, and dc resistivity. U.S. Geological Survey Open-File Report 2008-1109, $12 \mathrm{pp}$.

Bakula K., Salach A., Wziątek D. Z., Ostrowski W., Górski K. \& Kurczyński Z. (2017) - Evaluation of the accuracy of lidar data acquired using a UAS for levee monitoring: preliminary results. Int. J. of Remote Sens., 38:8-10, 2921-2937.

Busato L., Boaga J., Peruzzo L., Himi M., Cola S., Bersan S. \& Cassiani G. (2016) - Combined geophysical surveys for the characterization of a reconstructed river embankment. Engineering Geology, 211, 74-84.

Cardarelli E., Cercato M. \& Di Filippo G. (2010) - Geophysical investigation for the rehabilitation of a flood control embankment. Near Surf. Geophys., 8, 287-296. 
Chambers J. E., Gunn D. A., Wilkinson P. B., Ogilvy R. D., Ghataora G. S., Burrow M. P. N. \& Tilden Smith R. (2008) - Non-invasive timelapse imaging of moisture content changes in earth embankments using electrical resistivity tomography (ERT). In: Ellis, Yu, McDowell, Dawson \&Thom (eds.), Advances in transportation geotechnics. British Geological Survey, Nottingham, England, 475-480.

Chlaib H.K., Mahdi H., Al-Shukri H., Su M.M., Catakli A. \& Abd N. (2014) - Using ground penetrating radar in levee assessment to detect small scale animal burrows. J. of Appl. Geophys., 103, 121131.

Cho I. \& Yeom J. (2007) - Crossline resistivity tomography for the delineation of anomalous seepage pathways in an embankment dam. Geophys., 72(2), G31-G38.

Di Prinzio M., Bittelli M., Castellarin A \& Rossi Pisa P. (2010) Application of GPR to the monitoring of river embankments. J. of Appl. Geophys., 71, 53-61.

Fauchard C. \& Mériaux P. (2007) - Geophysical and geotechnical methods for diagnosing flood protection dikes. Editions Quae, ISBN 978-27592-00313, 128 pp.

Francese, R. \& Monteiro Santos F. (2014) - Towards a global approach to scan earthen levees. Expanded Abstracts Proceedings of: SEG Meeting, Denver, Colorado (October 26-31).

Gillip J. A. \& Payne J. D. (2011) - Geophysical characterization of the Lollie Levee near Conway, Arkansas, using capacitively coupled resistivity, coring, and direct push logging. US Geological Survey Data Series Report 640, 27 pp.

Hayashi K. \& Inazaki T. (2013) - Integrated geophysical exploration for safety assessment of levee systems. Proceedings of: GeoCongress 2013, San Diego, CA (March 3-6), Geoinstitute of the American Society of Civil Engineers, $10 \mathrm{pp}$.

Hilbich C, Fuss C. \& Hauck C. (2011) - Automated time-lapse ERT for improved process analysis and monitoring of frozen ground. Permafr. Periglac. Process. 22, 306-319.

Inazaki T., Kaneko M. \& Aoike K. (2016) - Detailed geophysical imaging of the shallow surfaces at an underseepage site behind of a levee. Proceedings of: Symposium on the Application of Geophysics to Engineering and Environmental Problems 2015, Austin, Texas (March 22-26).

Kuras O., Pritchard J. D., Meldrum P. I., Chambers J. E., Wilkinson P. B., Ogilvy R. D. \& Wealthall G. P. (2009) - Monitoring hydraulic processes with automated time-lapse electrical resistivity tomography (ALERT). Comptes Rendus Geoscience, 341, 10, 868885 .

Lapenna V., Lorenzo P., Perrone A., Piscitelli S., Rizzo E. \& Sdao F. (2005) - Case history: 2D electrical resistivity imaging of some complex landslides in Lucanian Apennine (Southern Italy). Geophys., 70, 11-18.
Longoni L., Papini M., Brambilla D., Barazzetti L., Roncoroni F., Scaioni M. \& Ivanov V.I. (2016) - Monitoring riverbank erosion in mountain catchments using terrestrial laser scanning. Remote Sens., 8, 241.

Malehmir A., Socco L.V., Bastani M., Krawczyk C.M., Pfaffhuber A.A. Miller R.D., Maurer H., Frauenfelder R., Suto K., Bazin S., Merz K. \& Dahlin T. (2016) - Near-Surface Geophysical Characterization of Areas Prone to Natural Hazards. Advances in Geophysics, 57, 51-146.

Morelli G. \& Francese R. (2013) - A fast and integrated geophysical imaging system for large scale levee monitoring. Proceedings of: Symposium on the Application of Geophysics to Engineering and Environmental Problems 2013, Denver, Colorado (March 17-21).

Perri M.T., Boaga J., Bersan S., Cassiani G., Cola S., Deiana R., Simonini P. \& Patti S. (2014) - River embankment characterization: The joint use of geophysical and geotechnical techniques. J. of Appl. Geophys., 110, 5-22.

Piegari E., Cataudella V., Di Maio R., Milano L., Nicodemi M. \& Soldovieri M. G. (2008) - Electrical resistivity tomography and statistical analysis in landslide modelling: A conceptual approach. J. of Appl. Geophys., 68, 2, 151-158.

Supper R., Ottowitz D., Jochum B., Kim J.H, Römer A., Baron I., Pfeiler S., Lovisolo M., Gruber S. \& Vecchiotti F. (2014) Geoelectrical monitoring: An innovative method to supplement landslide surveillance and early warning. Near Surf. Geophys., $12,133-150$.

Supper R., Romer A., Kreuzer G., Jochum B., Ottowitz D., Ita A. \& Kauer S. (2012) - The GEOMON 4D electrical monitoring system: current state and future developments. Instrumentation and data acquisition technology. Proceedings of: GELMON 2011, Berichte Geol. B.-A, 93, pp. 23-26. ISSN 1017 - 8880.

Tournadre V., Pierrot-Deseilligny M. \& Faure P. H. (2014) - UAV photogrammetry to monitor dykes - calibration and comparison to terrestrial LiDAR. International Archives of the photogrammetry, Remote Sensing and Spatial Information Sciences, XL-3/W1, 143-148.

Weller A., Lewis R. Tran C. Moller M. \& Scholz B. (2014) Geotechnical and Geophysical Long-term Monitoring at a Levee of Red River in Vietnam. J. of Environ. and Eng. Geophys., 19(3) 183-192.

Wernette P. et al. (2015) - GPR and EMI in complex environments emerging concepts, methods, instruments, and data analysis. Proceedings of: Symposium on the Application of Geophysics to Engineering and Environmental Problems 2015, Austin, Texas (March 22-26)

Wodajo L. \& Hickey C. (2017) - Seismic refraction and electrical resistivity cross-plot analysis of the Francis levee site. Proceedings of: Symposium on the Application of Geophysics to Engineering and Environmental Problems 2017, Denver, Colorado (March 19-23). 